\title{
Determining professionalism in Turkish students nurses
}

\author{
Ayişe Karadağ ${ }^{1}$ \\ Filiz Hisar ${ }^{2}$ \\ Bülent Çelik ${ }^{3}$ \\ Zehra Göçmen Baykara ${ }^{4}$
}

\begin{abstract}
Characteristics of the nursing profession include educational standards, professional organizations, commitment, autonomy, continuing education, body of knowledge and competencies, social value, and a code of ethics. This study was carried out with the aim of determining the professional attitudes of nursing students in Turkey. It was a descriptive study. This study was conducted in 25 nursing schools that provide graduate level nursing education in Turkey. The sample of the study included 1412 final year nursing students who were selected by random sampling from nursing schools offering education at bachelor level. Data was collected using a questionnaire, which included demographic characteristics of students and an Inventory to Measure Professional Attitudes in Student Nurses (IPASN). The mean score of IPASN was $4.1 \pm 0.5$ and the areas the highest mean scores were for autonomy, competence and continuous education whilst lowest ones were for cooperation, contribution to scientific knowledge, and participating in professional organizations. In conclusion, the overall mean scores of professional attitudes for nursing students were found to be satisfying and some recommendations were made to improve subgroups scores.
\end{abstract}

Keywords: Professionalism, nursing students, nursing, education, Turkey

\section{Introduction}

The education system makes an important contribution to the development of all professions, and should produce successful productive individuals who are held in high esteem by society (Hsieh and Hsu, 2013 and Tasocak, 2012). The term 'professionalism' refers to the conduct, qualities, and goals that characterize a profession and usually describes behaviours that are expected of the members of the profession (Hisar \& Karadağ, 2010). Healthcare providers demonstrate professionalism by attitudes, knowledge, and behaviours that reflect a multi-faceted approach to the regulations, principles, and standards underlying successful clinical practices (Gecgil et al., 2012; Bang et al., 2011).

Bachelor level nursing education in universities fulfils the requirements of the nursing profession more successfully than other way of educating or training nurses (Tasocak, 2012; Karadağ et al.,

\footnotetext{
${ }_{1}^{1}$ Proffesor, Koç University, School of Nursing, ayisekaradag@gmail.com

${ }^{2}$ Associate Proffesor, Necmettin Erbakan University Faculty of Health Science, Department of Nursing, filiz.hisar@gmail.com

${ }^{3}$ Associate Proffesor, Gazi University Faculty of Education, Department of Statistics, bulent06celik@gmail.com

${ }^{4}$ Associate Proffesor, Gazi University Faculty of Health Science, Department of Nursing, gocmenzehra@hayoo.com
} 
Karadağ, A., Hisar, F., Çelik, B., \& Baykara, G.Z. (2016).Determining professionalism in Turkish students nurses. International Journal of Human Sciences, 13(1), 674-682. doi:10.14687/ijhs.v13i1.2976

2007, Hisar \& Karadağ, 2010). These programs contribute to the education of professional nurses through curricula which include health, education and social science courses. Such programs aim to produce nurses with high levels of knowledge, effective critical thinking and problem solving capacities, good practical skills and an ability to develop evidence based practice (Karadağ et al. 2013, Hsieh \& Hsu, 2013). At a higher level nursing schools seek to produce future nurse leaders who can address a range of professional problems through evidence based practice, policy development and intervention and the mobilisation of professional opinion (Lin \& Wang, 2010; Çelik et al., 2012; Karagözoglu, 2009).

There is evidence that as individual education levels increase so does the commitment to professionalism and this in turn influences the acquisition of professional knowledge and the quality of care provided (Karadağ et al., 2007; Hisar \& Karadağ, 2010; Zhang \& Petrini, 2008). Nursing education varies across Europe but in recent years the European Parliament has indicated minimum standards for nurse education (Directive, 2005). In Turkey universities which have complied with these standards have courses which are explicitly concerned with developing professional knowledge, values and behaviour. In addition to this all courses on bachelor degree programs address aspects of professionalism, such as autonomy, in some way even though their primary focus is an area of nursing like medical and surgical care (Karadağ et al., 2007; Çevik \& Hisar, 2012). It is assumed that progression through such courses will equip students with the cognitive, emotional and practical skills to be effective professionals thereby raising the status of nursing as a profession (Atalay \& Tel, 2009; Karagözoglu, 2009).

However, achieving this aim of increasing the status of the profession is not easy as many studies indicate that nursing does not meet all the criteria for being a profession, especially with regard to education levels, professional knowledge and autonomy within the workplace (Karadağ et al., 2007; Hisar \& Karadăg, 2010; Çelik \& Hisar, 2012; Scot, 2008). In addition to this problem several studies demonstrate the fairly low level of professionalism amongst nursing students (Zhang \& Petrini, 2008; Bang et al., 2011). A possible reason for this low level is inadequate consideration of professional values in bachelor level education with this resulting from both poorly designed programs and inadequate educational quality (Zhang \& Petrini, 2008; Bang et al., 2011; Çelik et al., 2012).

Acquiring professionalism in nursing is central to professional development (Hisar et al., 2010). Educating and advising students on professionalism and educators being a role model during nursing education affect professional attitudes positively (Zhang \& Petrini, 2008; Hsieh \&Hsu, 2013). Development of professional attitudes ensures an improvement in the students' professional knowledge, skill and psychomotor behaviors. A professional attitude has great influence on the development of nursing students and the future quality of nursing (Zhang \& Petrini, 2008; Hisar et al., 2010). Professionalism in nursing results in enhanced patient care and greater job satisfaction among nurses, and nurse retention (Kwon \& Kim, 2011). In Turkey there is little research about the extent to which the characteristics of nursing students align with those required by successful professional nurses (Karagözoglu, 2009; Karagözoglu, 2008; Hisar et al., 2010). Furthermore, the few studies that have been conducted in Turkey have limitiations stemming from only considering certain aspects of professionalism as well as being based on small samples whose potential for generalisation is severely restricted. There is no study evaluating the professionalism of final year students using a scale whose validity and reliability has been confirmed and this study aims to fill that gap. The results obtained from the present study will demonstrate the professional attitudes of student nurses and thereby contribute to the planning of service delivery by those involved in nurse education, namely universities, research centres and professional organisations.

\section{Nursing Education in Turkey}

At present nursing education in Turkey is not wholly university based even though bachelor level degrees were introduced in 1955 and masters and doctoral level in 1968 (Kukulu, 2005). Nurses 
Karadağ, A., Hisar, F., Çelik, B., \& Baykara, G.Z. (2016).Determining professionalism in Turkish students nurses. International Journal of Human Sciences, 13(1), 674-682. doi:10.14687/ijhs.v13i1.2976

graduate from vocational high schools, two year associate degrees and four year bachelor degrees and until 2007 no differentiation in their duties and responsibilities was made (Hisar \& Karadağ, 2010). In that year the minimum requirement for nurse education was increased to bachelor level and by 2015 all vocational high schools for nurses will be closed (Nursing Law, 2007).

The minimum educational standards in nursing education in Turkey have been identified in line with the European Union Acquis in 2005 (Directive of the European Parliament, 2005). Part of the theoretical courses within the average 4600 hours of nursing curriculum is directly related to ensuring that a professional attitude and knowledge are supported. The core curriculum for nursing education and the subjects that should be included have also been identified. An attempt has been made to standardize the education in all nursing schools in Turkey (HUCEP, 2002).

\section{Purpose:}

This descriptive study was carried out in order to determine the professional attitudes of nursing students in Turkey.

\section{Method and material}

\subsection{Setting and sample}

86 nursing schools provided graduate level nursing education in Turkey and 6000 student were in their final year during the period when the data was collected (ÖSYS, 2010; Health Professions High School, 2010). The study sample comprised final year students from 25 schools which were randomly selected from institutions offering an undergraduate education in nursing in Turkey. The sample was composed of 1474 voluntary participants. Of these, $62(4.2 \%)$ did not complete the questionnaire and were excluded. The analyses were carried out using 1412 valid questionnaires.

Turkey has 7 geographical regions. 3 schools each from 3 regions and 4 schools each from the other 4 regions were chosen with the random sampling method, taking into account the number of students in each region, creating a sample of 25 schools.

\subsection{Data collection}

The questionnaire packages were mailed to the person in charge at the institutions approved to carry out the study, and were then handed out to the students. A questionnaire was sent with an information letter including the purpose of the study and a guide for completing the questionnaire. Data collection forms were filled out by the students themselves. The data were collected in a week at each school on predefined dates according to the fall semester dates for each school in 2010. All expenses were covered by the investigators.

\subsection{Instrument}

The current study was used to collect data through the Inventory to Measure Professional Attitudes in Student Nurses which was developed and validated by Hisar et al. 2010 (IPASN). The IPASN includes 28 items, and 8 subgroups: contribution to the increase of scientific information load (6 items, min:6, max: 30), autonomy (3 items, min:3, max: 15), cooperation (5 items, min:5, max: 25), competence and continuous education (3 items, min:3, max:15), participation in professional organisations and professional development ( 3 items, min:3, max: 15) working in committees (3 items, min:3, max: 15$)$, community service ( 2 items, min:2, max: 10 ), ethical codes, and theory (3 items, min:3, max: 15) and overall (28 items, min: 28, max: 140). Answers were given on a 5-item Likert-type scale $(1=\mathrm{I}$ do not agree at all; $2=\mathrm{I}$ do not agree; $3=\mathrm{I}$ am not certain; $4=\mathrm{I}$ partly agree and $5=\mathrm{I}$ completely agree). There was no cut-off point in the evaluation. High scores showed a highly professional attitude Cronbach's alpha for the internal consistency of the entire original IPASN was 0.90 . Cronbach's alpha value for this studys is 0.89 . Weighted average score of each subgroups were calculated. Subgroups were evaluated range of scores (Box: 1)

\subsection{Ethical considerations:}

Before the data were collected ethics comittee approval and institutional permissions were obtained. The students were asked to read the explanations related to the study on the front page of the questionnaire and to complete the questionnaire if they wished to participate in the study. 


\subsection{Data analysis}

The data were evaluated using the SPSS version 15.0 program (SPSS Inc., Chicago, IL, USA). Continuous variables were expressed as weighted means and standard deviations (Table 2) or overall means and standard deviations (Table 3) whereas percentages and frequencies were used for categorical variables (Table 1). For the continuous variables parametric test conditions were tested. Analysis of the difference between two groups was performed by Student's t test. A p value less than 0.05 was considered as statistically significant.

\section{Results}

Table 1. The demographic characteristics of students (n: 1412)

\begin{tabular}{lrr}
\hline Characteristics & N & $\mathbf{\%}$ \\
\hline Gender & 1232 & 87.3 \\
Female & 180 & 12.7 \\
Male & & \\
Participation in professional activities & 724 & 51.3 \\
Yes & 688 & 48.7 \\
No &
\end{tabular}

\section{Satisfaction with choosing nursing}

Satisfied

Dissatisfied

Participation in community activities

Yes

No

\section{Would choose nursing again}

Yes

No

\section{Reason for choosing nursing*}

Ease of finding a job

Own desire

Wishes of family and friends

Sufficient enty requirements

* participants gave more than one answer

As seen in Table 1, $87.3 \%$ of the participants were female, $70 \%$ satisfied with choosing nursing as a profession, and $44.1 \%$ indicated that they would chose nursing again. 
Karadağ, A., Hisar, F., Çelik, B., \& Baykara, G.Z. (2016).Determining professionalism in Turkish students nurses. International Journal of Human Sciences, 13(1), 674-682. doi:10.14687/ijhs.v13i1.2976

Table 2. The distribution of the weighted mean scores of the IPASN sub groups according to the number of questions

\begin{tabular}{|l|c|c|}
\hline Subgroups & Mean & SD \\
\hline 1.Contribution to scientific knowledge & 3.8 & 0.9 \\
2. Autonomy & 4.7 & 0.6 \\
3. Cooperation & 3.5 & 0.9 \\
4. Competence, Continuous education & 4.4 & 0.8 \\
5. Participating in professional & & \\
organizations and professional & 4.1 & 0.9 \\
development & 4.4 & 0.8 \\
6.Community service & 4.2 & 0.7 \\
7. Working in committees & 4.1 & 0.7 \\
8. Ethical codes & $\mathbf{4 . 1}$ & $\mathbf{0 . 5}$ \\
\hline Overall (28 items) & & \\
\hline
\end{tabular}

In Table 2, distribution of the weighted mean scores of the IPASN sub groups according to the number of questions are shown. The distribution of the mean scores of students obtained from the IPASN subscales are shown. The overall mean score of students was $4.1 \pm 0.5$ and the areas the

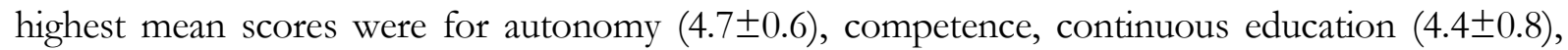
community services $(4.4 \pm 0.8)$ and working in comittees $(4.2 \pm 0.7)$ whilst lowest ones were for cooperation $(3.5 \pm 0.9)$, contribution to scientific knowledge $(3.8 \pm 0.9)$, participating in professional organizations (4.1 \pm 0.9$)$, and professional development and ethical codes and theory (4.1 \pm 0.7$)$.

Table 3 IPASN overall mean scores of students according to socio-demographics characteristic

\begin{tabular}{|c|c|c|c|c|c|}
\hline Characteristic & $\mathrm{n}$ & Mean & SD & Test & $\mathbf{P}$ \\
\hline \multicolumn{6}{|l|}{ Gender } \\
\hline Female & 1232 & 114.8 & 14.4 & \multirow{2}{*}{$t=8.2$} & \\
\hline Male & 180 & 105.1 & 16.4 & & \\
\hline
\end{tabular}

\section{Work status}

Employed

Not employed

$102 \quad 113.7 \quad 15.6$

$1310 \quad 113.6 \quad 15.0$

$$
\mathrm{t}=0.01 \quad 0.960
$$

Satisfaction with choosing nursing

Satisfied

Unsatisfied

$989 \quad 116.1 \quad 14.0$

$423 \quad 107.9 \quad 15.8$

Participation in professional activities

$\begin{array}{llllll}\text { Yes } & 724 & 115.4 & 14.6 & & \\ \text { No } & 688 & 111.6 & 15.2 & & \end{array}$


Karadağ, A., Hisar, F., Çelik, B., \& Baykara, G.Z. (2016).Determining professionalism in Turkish students nurses. International Journal of Human Sciences, 13(1), 674-682. doi:10.14687/ijhs.v13i1.2976

\section{Participation in community activities}

\begin{tabular}{lccccc} 
Yes & 483 & 118.1 & 13.8 & & \\
No & 929 & 111.2 & 15.0 & $\mathrm{t}=8.3$ & $<0.000$ \\
Would choose nursing again & & & & & \\
Yes & 623 & 116.6 & 14.6 & & \\
No & 789 & 111.2 & 14.9 & $\mathrm{t}=6.6$ & $<0.000$ \\
Overall (28 Items) & $\mathbf{2 8}$ & $\mathbf{1 4 0}$ & $\mathbf{1 1 3 . 6}$ & $\mathbf{1 5 . 0}$ & \\
\hline
\end{tabular}

As seen in Table 3, overall mean score of female students (114 \pm 14.4$)$ had higher scores than male ones (105.1 \pm 16.4$)$. The mean IPASN score was highest in the group who had been satisfied with choosing nursing as a profession (116.1 \pm 14.0$)$, participate in professional activities (115 \pm 14.6 ), participate in community activities (118.1 \pm 13.8$)$, and would choose nursing again (116.6 \pm 14.6$)$. The difference between the groups was found to be statistically significant $(P<0.05)$.

Box:1

\begin{tabular}{|lll|}
\hline Answers & Score & Range of score \\
I completely agree & 5 & $4.20-5.00$ \\
I partly agree & 4 & $3.40-4.19$ \\
I am not certain & 3 & $2.60-3.39$ \\
I do not agree & 2 & $1.80-2.59$ \\
I do not agree at all & 1 & $1.00-1.79$ \\
\hline
\end{tabular}

\section{Discussion}

In the present study, if 140, which is the highest score that can be obtained from attitude inventory is taken as reference, it can be said that professionalism of students is at a satisfactory level except for the subscales of cooperation and contribution to the enhancement of scientific knowledge (Table 2). This result is important in that it shows that many institutions training nurses have come closer to their aims (Gazi University, 2013; Hacettepe University, 2013). Our findings are generally congruent with the results of similar study carried out in order to determine the opinions of last year nursing students regarding professionalism in nursing. In the study $(\mathrm{n}=150)$ conducted by Atalay et al., (2004) it was established that $98 \%$ of the students planned to work in accordance with ethical codes after graduation, $96 \%$ to participate in social services, $93.3 \%$ to participate in studies for making nursing more independent, $85.3 \%$ to subscribe to a nursing journal and $70 \%$ to become a member in their professional organization. The findings of present study will be addressed under the headings below.

\section{Contribution to the scientific knowledge}

Level of education is one of the basic criteria of professionalism and it should be constantly developed in order to follow scientific developments and to apply evidence based practice (Killen \& Safwert, 2007; Hisar \& Karadağ, 2010). Master and PhD programs are the essential means of producing knowledge. In addition, activities such as carrying out studies in collaboration with different disciplines and institutions, and participating in certificate programs and congresses contribute to increasing the level of scientific knowledge (Scott, 2008). Although post graduate training started in Turkey in 1968 the subscale of contribution to the enhancement of scientific 
Karadağ, A., Hisar, F., Çelik, B., \& Baykara, G.Z. (2016).Determining professionalism in Turkish students nurses. International Journal of Human Sciences, 13(1), 674-682. doi:10.14687/ijhs.v13i1.2976

knowledge is the subscales in which the students scored the lowest (Table 2). Here, the attitude of students towards graduate, post graduate degrees and $\mathrm{PhD}$ was questioned. The overall mean score of IPASN was higher in students satisfied with having chosen the profession of nursing, and having indicated that they would choose nursing again (Table 3). Individuals who choose their profession on their own will think of advancing professionally after graduation. Leaving the profession after graduation and not maintaining professional development are amongst the serious problems nursing is faced with (Karadağ, 2002).

\section{Cooperation}

In the present study one of the lowest score was obtained in the subscale 'cooperation' (Table 2). Yet, nursing is a discipline based upon a holistic care approach, and which should be conducted through cooperation between team members. It is thought that the fact that students do not participate in team work during clinical education and do not witness it in many areas may have been influential in these results. Some research has indicated a low level of professional teamworking between medical and nursing students (Hsieh \& Hsu, 2013; Moroğlu, 2007), and team consciousness was undeveloped among health care workers employed in hospital (Moroğlu, 2007).

\section{Autonomy}

In the present study, the subscale autonomy has one of the highest value (Table 2). Similarly, in a study on the last year nursing students of a health sciences faculty $(n=326)$ it was established that autonomy level of students was slightly higher than the mean values (Karagözoglu, 2008). However, in the literature in comparative studies carried out with different student groups, autonomy level of nursing students was found to be generally low (Atalay et al., 2004; Boughn, 1988). Another study, compared the autonomy level of nursing students with that of education, social science, natural science and economy students and found that autonomy level of nursing education faculty students were lower than other departments (Boughn, 1988). According to the literature as nursing students tend to obey and be dependent; their autonomy does not develop adequately (Karagözoglu, 2008; Karagözoglu, 2009).

Autonomy is one of the most important professional characteristics (Karadağ et al., 2007; Hisar \& Karadağ, 2010; Karagözoglu, 2009). Autonomy refers to the making decisions independent of others and acting independently in parallel to these decisions (Oweis, 2005). In the literature, it has been stated that the higher the autonomy levels of the individuals carrying out a profession, the higher the autonomy of the profession (Çelik \& Hisar, 2012; Hisar, \& Karadağ, 2010). However, in a previous study we found that autonomy status of nurses was at a very low level $(n=1047)$ (Karadağ et al., 2007). When these two findings are evaluated together, it may be thought that the causes of low autonomy in nursing are related to hierarchy in work place and legal regulations making nurses dependent (Karadağ et al., 2007; Hisar \& Karadağ, 2010). Another important point here is to train students on how to transfer their positive attitude towards autonomy into behavior after graduation. According to the literature the level of autonomy in their colleagues influences the autonomy of students (Karagözoglu, 2008; Karagözoglu, 2009).

\section{Ethics and participation in professional organisations}

The present study indicates that student attitudes towards professional ethical codes, and participation in professional organisations is relatively low (Table 2). Participation in professional organisations, which is the most important determinant of professionalism it is at quite a low level in nursing (Karadağ et al., 2007; Hisar \& Karadağ, 2010). The largest professional nurse organisation in Turkey is the Turkish Nurses Association and some of the students were keen to become members when they graduated. Despite this research indicated that the actual level of participation in professional organisation amongst graduate nurses was quite low. More research 
Karadağ, A., Hisar, F., Çelik, B., \& Baykara, G.Z. (2016).Determining professionalism in Turkish students nurses. International Journal of Human Sciences, 13(1), 674-682. doi:10.14687/ijhs.v13i1.2976

needs to be conducted to determine how this positive attitude towards membership can be converted into active participation.

\section{Conclusions and recommendations}

In conclusion, the results of the current study indicate that the attitudes of nursing students were relatively low in some subscales of professionalism. Highest scores of professional attitudes were obtained in the subscales autonomy, community service, and competence, continuous education whereas their scores were lowest in contribution to scientific knowledge, and cooperation. The scores of students who choose nursing department by themselves, who are female, who are satisfied with their choice of nursing department and who participate in scientific activities and public services were higher, with a statistically significant difference between groups.

In view of these findings, our recommendations as follows:

- The subject of professional nursing should be included in the curriculum

- Students should be encouraged to carry out investigations

- The participation of students in scientific activities especially congresses should be encouraged

- Student membership of professional organisations should be facilitated

- Planning and carrying out projects aiming to protect and improve public health together with students

- Helping the students to practice in areas with high professional values and team cooperation

\section{References}

Atalay, E., Güler, N., Özlü, S., Demir, Ş., Karadağ, A., (2004). Opinion of final year nursing students on: professionalism. 3. International Student Nursing Congress. (pp.92). Abstract Book, Turkey: Odak Press, (in Turkish),

Atalay, M., Tel, H., (1999). Bachelor's education in nursing in the next century. C.Ü. Journal of School of Nursing 3, 48-56, (in Turkish).

Bang, K.S., Kang, J.H., Jun, M.H., Kim, H.S., Son, H.M., Yu, S.J., Kwon, M.K., Kim, J.S., (2011). Professional values in Korean undergraduate nursing students. Nurse Education Today 31(1), $72-75$.

Boughn, S.A., (1988). A lack of autonomy in the contemporary nursing student: a comparative study. Journal of Nursing Education 27(4),150-155.

Geçkil, E., Ege, E., Akın, B., Göz, F., (2012). Turkish version of the revised nursing professional values scale: Validity and reliability assessment. Japan Journal of Nursing Science 9(2),195-200.

Çelik, S., Hisar, F., (2012). The Influence of the professionalism behaviours of nurses working in health instutiations on job satisfaction. International Journal of Nursing Practice 18(2),180-187.

Directive, 2005. 2005/36/EC of The European Parliament and of the Council on the recognition of the professional qualifications, http://eur-lex. europa.eu /LexUriServ/LexUriServ. do?uri=OJ:L:2005:255:0022:0142:EN: PDF. Accessed 11 january 2013.

Gazi University, (2013). Faculty of Health Sciences Nursing Department educational and professional objectives, goals. http://sbf.gazi.edu.tr/posts/view/title/egitimsel-veprofesyonel amaclar \%2C-hedefler-11314. Accessed 1 February 2013.

Hacettepe University, Faculty of Nursing and professional objectives, goals, http://www.hemsirelik.hacettepe.edu.tr/. Accessed 1 February 2013.

Health Professions High School, (2010) Retrived July 20, 2010 from http://sdb.meb.gov.tr/ tasra.html, (in Turkish)

Hisar, F., Karadağ, A., (2010). Determining the professional behavior of nurse executives. Intational Journal Nursing Practice 16(4),335-341.

Hisar, F., Karadağ, A., Kan, A., (2010). Development of an instrument to measure professional attitudes in nursing students in Turkey. Nurse Education Today 30(8),726-730. 
Karadağ, A., Hisar, F., Çelik, B., \& Baykara, G.Z. (2016).Determining professionalism in Turkish students nurses. International Journal of Human Sciences, 13(1), 674-682. doi:10.14687/ijhs.v13i1.2976

Hsieh, S.I., Hsu, L.L., (2013). An outcome-based evaluation of nursing competency of baccalaureate senior nursing students in Taiwan. Nurse Education Today 33 (12),1536-1545.

HUÇEP YÖK Hemşirelik Ulusal Çekirdek Eğitim Programı (HUÇEP) Komisyon Raporu 2002 (YÖK'ün Üniversitelere gönderdiği 16.09.2003-019528 no'lu yazısı). (in Turkish).

Karadağ, A., (2002). Nursing as a profession, Atatürk. University Journal of School of Nursing 5, 55-63. (in Turkish).

Karadağ, A., Hisar, F., Elbaş, N. Ö., (2007). The level of professionalism among nurses in Turkey. Journal of Nursing Scholarship 39(4),371-374.

Karadağ, A., Addis, G., Çalışkan, N., Göçmen-Baykara, Z., Sezgin F., (2013). A longitudinal study of perceptions of self-concept and professional self-concept in Turkish nursing students. International Journal of Human Sciences 10(1),1355-65

Karagözoglu, S., (2008). Level of autonomy of Turkish students in the final year of university baccalaureate degree in health-related fields. Nursing Outlook 56 (2),70-77.

Karagözoglu, S., (2009). Nursing students' level of autonomy: a study from Turkey. Nurse Education Today 29(2),176-87.

Killen, M. L., Safwert, K. J., (2007). Socialization to professional nursing. In: Creasia JL, Parker BJ., (eds). Conceptual Foundation The Bridge to Professional Nursing Practice. Mosby: USA, Elsevier, pp.49_ 76.

Kukulu, K., (2005). Nursing in Turkey. Nurse Educator 308(3),101-103.

Kwon, M.K., Kim, J.S., (2011). Professional values in Korean undergraduate nursing students. Nurse Education Today 31 (1), 72-75

Lin, Y.H., Wang, L.S., (2010). A Chinese version of the revised nurses professional values scale: Reliability and validity assessment. Nurse Education Today 30(6),492-498

Martin, P., Yarbrough, S., Alfred, D., (2003). Professional values held by baccalaureate and associate degree nursing students. Journal of Nursing Scholarship 35(3),291-296.

Moroğlu, D., (2007). The determination of perspectives of Cumburiyet University Hospital' medical staff on teamwork, (Master's thesis). Sivas, Turkey: (in Turkish)

Nursing Law, 2007. Available from URL: http://www.mevzuat.adalet.gov.tr/html/976.html. Accessed 11 january 2013. (in Turkish)

ÖSYS., 2010. Guide to higher education programs and quotas, Table 4 Center for the higher education graduate programs and student placement, Retrived July 20, 2010 from:ftp://dokuman.osym.gov.tr/2010/2010_OSYS_TERCIH_KILAVUZU/2010_OSY S_Tablo4.pdf (in Turkish)

Oweis, A.I., (2005). Bringing the professional challenges for nursing in Jordan to light. International Journal of Nursing Practice 11(6),244-249.

Scott, S.D., (2008). 'New professionalism' - shifting relationships between nursing education and nursing practice. Nurse Education Today 28, 240-245.

Tasocak, G., (2012). Overview of Nursing and Nursing Education (In) Atabek-Asti T., Karadağ A., (Eds), Fundamentals of Nursing, Nursing Science and Art. Akademi Publications, İstanbul/Turkey.1821. (In Turkish).

Zhang, H.F., Petrini, M.A., (2008). Factors influencing Chinese undergraduate nursing students' perception of the nursing profession. International Nursing Review 55(3), 274-280. 